\title{
What if the 25 October 2011 event that struck Cinque Terre (Liguria) had happened in Genoa, Italy? Flooding scenarios, hazard mapping and damage estimation
}

\author{
Francesco Silvestro ${ }^{1}$, Nicola Rebora ${ }^{1}$, Lauro Rossi ${ }^{1}$, Daniele Dolia ${ }^{1}$, Simone Gabellani $^{1}$, Flavio Pignone ${ }^{1}$, \\ Eva Trasforini ${ }^{1}$, Roberto Rudari ${ }^{1}$, Silvia De Angeli ${ }^{1,2}$, and Cristiano Masciulli ${ }^{3}$ \\ ${ }^{1}$ CIMA Research Foundation, Savona, Italy \\ ${ }^{2}$ WRR Programme, UME School, IUSS-Pavia, Italy \\ ${ }^{3}$ IREN, Genoa, Italy
}

Correspondence to: Francesco Silvestro (francesco.silvestro@cimafoundation.org)

Received: 6 April 2016 - Published in Nat. Hazards Earth Syst. Sci. Discuss.: 7 April 2016

Revised: 1 July 2016 - Accepted: 5 July 2016 - Published: 3 August 2016

\begin{abstract}
During the autumn of 2011 two catastrophic, very intense rainfall events affected two different parts of the Liguria Region of Italy causing various flash floods. The first occurred in October and the second at the beginning of November. Both the events were characterized by very high rainfall intensities $\left(>100 \mathrm{~mm} \mathrm{~h}^{-1}\right)$ that persisted on a small portion of territory causing local huge rainfall accumulations

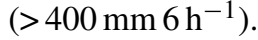

Two main considerations were made in order to set up this work. The first consideration is that various studies demonstrated that the two events had a similar genesis and similar triggering elements. The second very evident and coarse concern is that two main elements are needed to have a flash flood: a very intense and localized rainfall event and a catchment (or a group of catchments) to be affected. Starting from these assumptions we did the exercise of mixing the two flash flood ingredients by putting the rainfall field of the first event on the main catchment struck by the second event, which has its mouth in the biggest city of the Liguria Region: Genoa.

A complete framework was set up to quantitatively carry out a "what if" experiment with the aim of evaluating the possible damages associated with this event. A probabilistic rainfall downscaling model was used to generate possible rainfall scenarios maintaining the main characteristics of the observed rainfall fields while a hydrological model transformed these rainfall scenarios in streamflow scenarios. A subset of streamflow scenarios is then used as input to a 2D hydraulic model to estimate the hazard maps, and finally a
\end{abstract}

proper methodology is applied for damage estimation. This leads to the estimation of the potential economic losses and of the risk level for the people that stay in the affected area.

The results are interesting, surprising and in a way worrying: a rare but not impossible event (it occurred about $50 \mathrm{~km}$ away from Genoa) would have caused huge damages estimated between 120 and EUR 230 million for the affected part of the city of Genoa, Italy, and more than 17000 potentially affected people.

\section{Introduction}

Flash floods are one of the most disastrous natural hazards that affect citizens in many parts of the world causing high risk for them and for their goods and activities. Many types of flash floods exist, but in a great number of cases they are caused by very intense (i.e., $50-150 \mathrm{~mm} \mathrm{~h}^{-1}$ ) and localized rainfall events that persist on the same area for hours (i.e., 4-12 h) causing large accumulation of precipitation and fast response of catchments with $\mathrm{O}$ (area) $10^{0}$ to $10^{3} \mathrm{~km}^{2}$ (Gaume and Borga, 2008; Quevauviller, 2014). Many authors focused on the analysis of these events, their genesis and their ground effects (Amengual et al, 2007; Barthlott and Kirshbaum, 2013; Gaume et al., 2009; Marchi et al., 2009; Delrieu et al., 2006; Massacand et al., 1998; Roth et al., 1996), and a lot of research was carried out to improve their predictability in terms of rainfall with numerical weather prediction sys- 


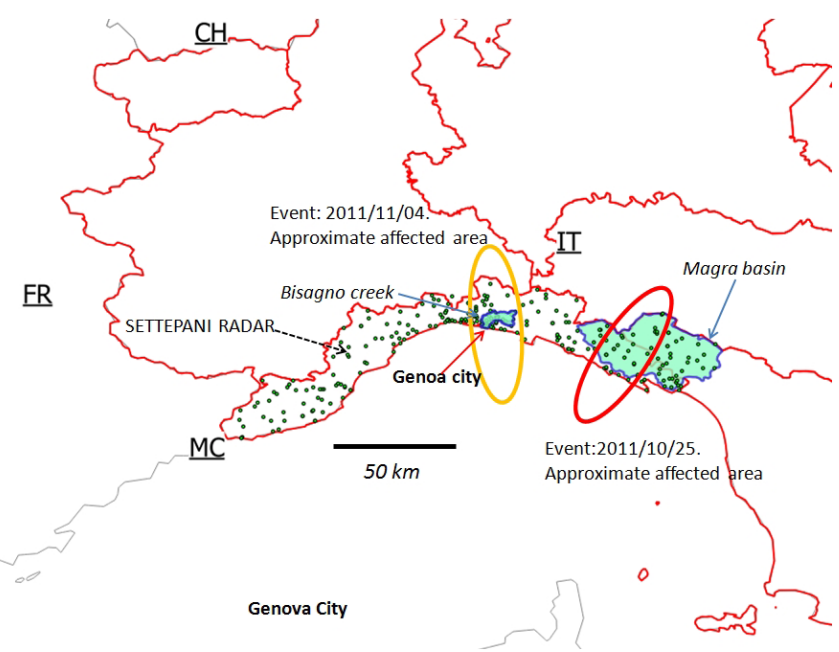

Figure 1. Main areas struck by the two intense events that occurred between October and November 2011 (red and yellow ellipses). The watermarks of the Bisagno creek and of the Magra basin are reported in blue. The green dots are the rain gauges of the regional network. Red lines represent the regions in northwestern Italy.

tems (NWPSs) (Buzzi et al., 2014; Fiori et al., 2014) and in terms of streamflow (Alfieri et al., 2012; Siccardi et al., 2005; Silvestro and Rebora, 2014; Versini et al., 2014) even referring to hydrological nowcasting techniques (Borga et al., 2011; Liechti et al., 2013; Silvestro et al., 2015a)

During the autumn 2011 two flash floods struck the Liguria Region of Italy, claiming a total of 19 victims and causing a large amount of damage. The first flash flood occurred on 25 October 2011; it affected the Cinque Terre coastal towns of Monterosso and Vernazza in the eastern Liguria Region and caused the flooding of Magra river. The second event occurred 9 days later, on 4 November, at about $50 \mathrm{~km}$ of distance and mainly affected the city of Genoa with the flooding of Bisagno creek (see Fig. 1).

They became two "school cases" studied by many scientists around the world during the last 5 years, awakening the interest of the local authorities and of the civil protection actors regarding these type of calamities. Due to the large amount of damage and the numerous victims, they caused a general increase of the sensibleness of the citizens of the areas stricken by natural hazards.

Both the events were characterized by very high rainfall intensities and a highly persistent localization. The V-shaped precipitation structure was observed in both cases; the rainfall cells were anisotropic with the dimension of major axis of $50-60 \mathrm{~km}$ oriented in the direction perpendicular to the coast and the dimension of minor axis of 5 to $15 \mathrm{~km}$ (see Rebora et al., 2013). The maximum hourly rainfall intensities measured by a gauge were around $160 \mathrm{~mm}$ during the 4 November event and $150 \mathrm{~mm}$ during the 25 October event, while the $24 \mathrm{~h}$ accumulation was respectively around 500 and $540 \mathrm{~mm}$. Figure 2 shows the maximum accumulated rainfall

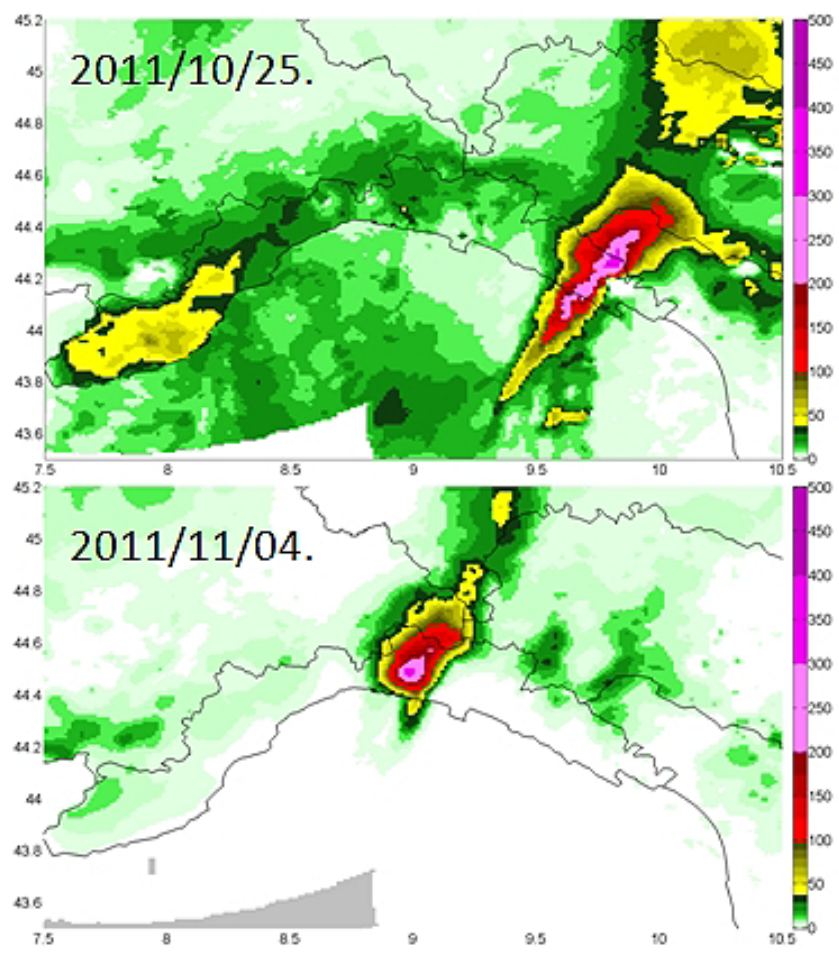

Figure 2. Comparison of the $6 \mathrm{~h}$ maximum accumulated rainfall (mm) for the events on 25 October 2011 (top panel) and on 4 November 2011 (bottom panel).

on $6 \mathrm{~h}$ for the two events obtained merging the radar data from Italian national mosaic and gauge data with the algorithm described in Sinclair and Pegram (2005).

In both cases the effects in terms of discharge were important. The Bisagno creek $\left(\operatorname{area}=98 \mathrm{~km}^{2}\right)$ flooded on 4 November reaching a peak flow with return period $(T)$ around 30 years while Magra basin $\left(\operatorname{area}=1660 \mathrm{~km}^{2}\right)$ flooded on 25 October reaching a peak flow with $T$ around 50 years; in some small tributaries the peak flow had $T$ larger than 100 years during both the events.

Silvestro et al. (2012) provided a hydrological description of the 4 November event highlighting the efficacy of the forecast approach adopted by the local authorities. Rebora et al. (2013) gave a detailed analysis of what happened based on a wide collection of observed data. Buzzi et al. (2014) conducted a series of experiments based on a NWPS to understand the genesis of the two events. Nardi and Rinaldi (2014) analyzed the changes in space and time of channel patterns in response to the major flood of the Magra basin during the 25 October event. Davolio et al. (2015) analyzed the improvements in the flood forecast of the two events due to the horizontal spatial resolution increase of a NWPS used to trigger a probabilistic flood forecast chain. Some of the authors of this work were involved as co-authors in many of the aforementioned articles, and recently a very simple but interest- 
ing question arose: what would have been the impacts if the storm event of 25 October had hit the city of Genoa?

This is a reasonable question. In fact various authors (Buzzi et al., 2014; Rebora et al., 2013; Fiori et al., 2014) demonstrated that the two events had similar characteristics and a similar genesis. In addition many of the conditions that triggered the rainfall event were the same.

We tried to answer to this question by setting up a complete flood forecasting chain that combines a rainfall downscaling model, a hydrological model, a 2-D hydraulic model and a methodology to estimate damages.

The rainfall downscaling model and the hydrological model are part of the flood forecasting framework presented in Silvestro et al. (2015b) and already employed to study the predictability of a flash flood event. The rainfall field observed on 25 October 2011 in the eastern part of Liguria is artificially moved on Bisagno creek following a probabilistic approach to generate possible streamflow scenarios.

In order to produce a damage assessment analysis, a subset of the streamflow scenarios are used as input to a 2-D hydraulic model to estimate the related hazard maps and then, using information about exposure, an appropriate methodology is applied to estimate the potential damage and the risk level for the population. The latter is based on a standard approach but a series of novel elements was introduced in order to adapt the method to the particular study area.

Currently, the planning and designing of structures and infrastructures which have the purpose of mitigating the flood risk is carried out based on the estimation of peak flow with a certain return period $T$ (as an example in Italy the reference $T$ is 200 years), but no indications on the evolution of the discharge event are provided. Given a return period, different assumptions concerning the evolution, duration of the event (shape of hydrograph, total volume, etc.) can make a real difference in terms of impacts. The presented work demonstrates that quantitative indications on possible direct impacts can be obtained, at least in some cases, following a "worstcase" scenario perspective based on real possible events. The presented approach is robust and it faces the problem in a probabilistic way giving possible flooding scenarios starting from a real precipitation event.

In this way a multidisciplinary approach was implemented in order to answer to the initial scientific question: what if the 25th October 2011 event that struck Cinque Terre had happened in Genoa (Liguria, Italy)?

The paper is organized as follows: Sect. 2 describes the study area and the hydrometeorological data set; Sect. 3 shows the material and models used to carry out the experiments. In Sect. 4 the results are reported, and finally the paper concludes in Sect. 5 with the discussion and conclusions.

\section{Hydrometeorological data set and study area}

Bisagno creek is placed in the center of the Liguria Region in northern Italy (Fig. 1). It drains a total area of approximately $98 \mathrm{~km}^{2}$, and it is characterized by steep slopes due to the a mountainous topology given its proximity to the Apennines. The minimum and maximum elevations are 0 and $1100 \mathrm{~m}$ respectively, while the mean elevation is about $370 \mathrm{~m}$. The majority of the Bisagno basin is covered with vegetation characterized by forest, meadows and brushes, but the last $10 \mathrm{~km}$ of its riverbed is heavily urbanized; there are residential areas, factories and infrastructures which are exposed to a high risk of flooding. Along the last $1.5 \mathrm{~km}$, towards the mouth, the river flows under a cover.

The territory of Liguria is monitored by a meteorological network, named OMIRL - "Osservatorio Meteo-Idrologico della Regione Liguria”. It is the official network managed by the Civil Protection Agency of Liguria Region and it is part of the Italian rain gauge network managed by the Italian Civil Protection Department (Molini et al., 2009). This system provides rain gauge measurements with 5-10 min timesteps. The network counts a total number of about 200 instruments over the region reaching an average density of one rain gauge per $40 \mathrm{~km}^{2}$. Stations with other sensors (temperature, radiation, wind, air humidity, etc.) are present, even though their densities are lower than the rain gauge density.

Bisagno creek is a very well-instrumented and wellmonitored catchment with a rain gauge density of about one rain gauge per $10 \mathrm{~km}^{2}$.

For the analyzed basin, level gauge data are available at the cross section Passerella Firpo, which has an upstream area of about $93 \mathrm{~km}^{2}$. The level data are combined together with a rating curve in order to estimate the observed streamflow.

The Liguria Region (Fig. 1) is covered by a Doppler polarimetric C-band radar, located on Mount Settepani at an altitude of $1386 \mathrm{~m}$ that works operationally with 10 min scansion time (e.g., time interval when radar data are available). Rainfall fields are provided with $1 \times 1 \mathrm{~km}$ spatial resolution.

\section{Material and models}

\subsection{Flood forecast framework}

A flood forecast framework (hereafter FFF) is described in Silvestro et al. (2015b), and it is made by two elements: (i) RainFARM (Rebora et al., 2006a, b), which is a rainfall downscaling model used for generating an ensemble of precipitation fields that are consistent with large-scale predictions issued by meteorological models (Laiolo et al., 2014) and/or by expert forecasters (Silvestro et al., 2011) and (ii) Continuum (Silvestro et al., 2013, 2015c), which is a continuous distributed hydrological model.

The setting and the parameters of the Continuum model are obtained from previous application (Silvestro et al., 

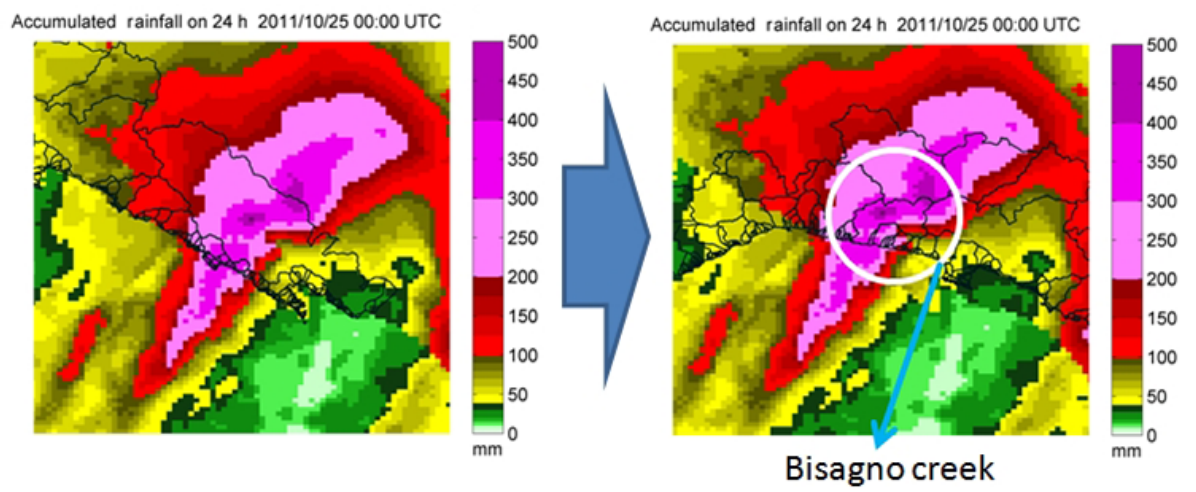

Figure 3. The 25 October 2011 accumulated rainfall over $24 \mathrm{~h}$. Left panel indicates observed rainfall field and the right panel the hypothetical rainfall field obtained by the rigid translation of the observed rainfall field from the original position to the Bisagno creek.

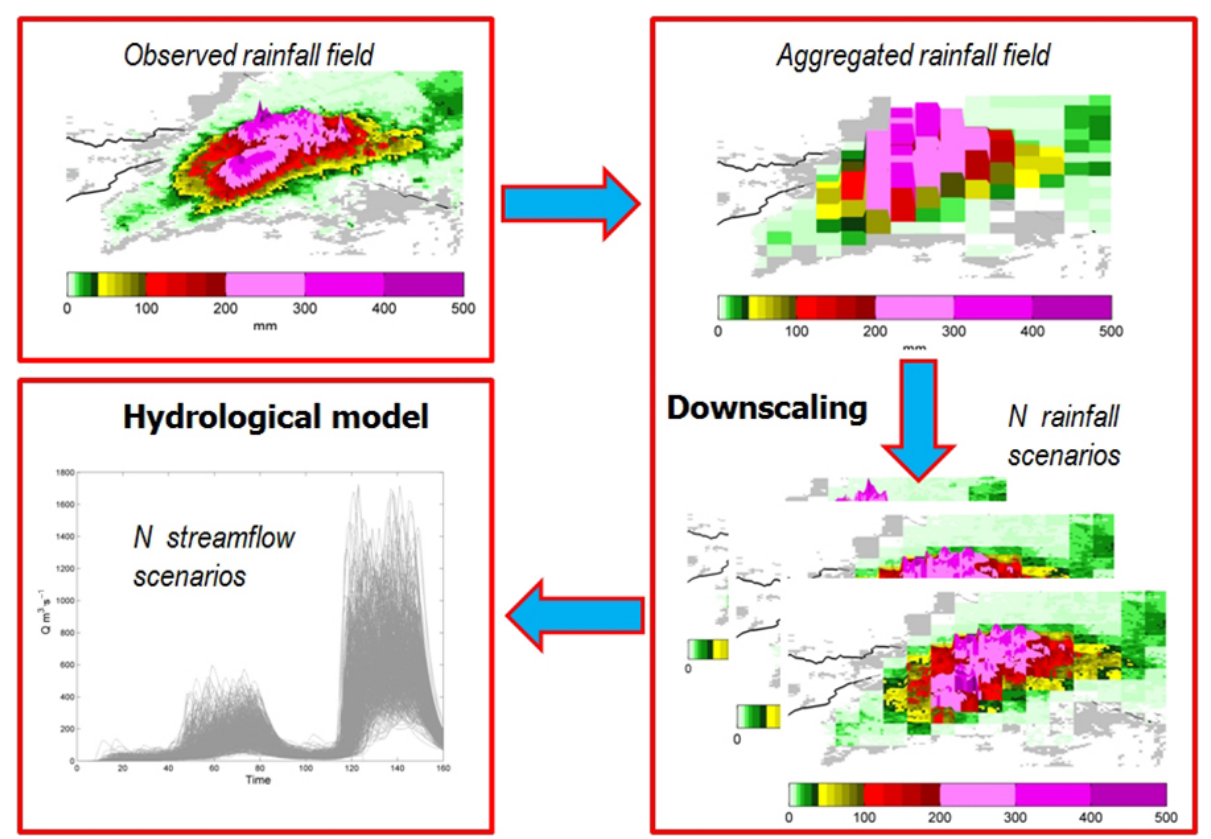

Figure 4. Schematization of the flood forecast framework made by a downscaling model and a hydrological model. In this application the rainfall field is the one reported in Fig. 3.

2015b). The spatial resolution is $90 \mathrm{~m}$ and the temporal resolution is $10 \mathrm{~min}$. The considered reference model section corresponds to the location of Passerella Firpo level gauge on Bisagno creek; there the drainage area is $93 \mathrm{~km}^{2}$. The model is run using meteorological observations from ground stations starting from 1 January 2011 in order to estimate the values of the state variables at the beginning of the event.

We presume to know the total volume of precipitation at a certain large scale (rainfall volume: RV) deriving it from the observations.

The rainfall field that occurred from 00:00 UTC of 25 October 2011 to 00:00 UTC of 26 October 2011 was estimated by the radar rainfall estimation merged with rain gauge data using the conditional merging $(\mathrm{CM})$ technique described in
Sinclair and Pegram (2005). This rainfall field is named "true rainfall field" (hereafter TRF). The algorithm is applied at hourly scale. The TRF is artificially moved in order to affect the Bisagno creek with the following approach: the point where the accumulated rainfall over $24 \mathrm{~h}$ has the maximum value was made coinciding with the centroid of the basin (see Fig. 3). The TRF is then aggregated at different spatial and temporal scales. Finally it is downscaled to generate possible streamflow scenarios that affect the city of Genoa; this is to the knowledge of the authors a quite novel way to set up a "what if" experiment. In fact, on the one hand it allows the use of a real event (not built with standard methods based on the generation of synthetic events); on the other hand it allows accounting for the uncertainties and possible variability 
of spatial and temporal patterns at small scales (i.e., $1-8 \mathrm{~km}$, 10-60 min) of a rainfall field with a certain volume of precipitation and a certain spatiotemporal structure at larger scales (i.e., 8-30 km, 60-360 min)

The RainFARM parameters are estimated directly by the radar rainfall fields in order to determine the correct spatial and temporal characteristics of the rainfall event.

A domain (hereafter DV) of $32 \times 32 \mathrm{~km}$ centered where the accumulated rainfall over $24 \mathrm{~h}$ has the maximum value was considered for computational reasons.

The TRF is aggregated on the DV at various time and spatial scales (hereafter RS), from coarse to fine scales, obtaining an aggregated rainfall field (hereafter AF). The total volume of rainfall of AF is conserved and equal to the volume of TRF.

The spatial and temporal aggregation scales are chosen in order to account for the possible uncertainties related to the temporal and spatial distribution of the rainfall and to easily compute fast Fourier transform (FFT) (Rebora et al., 2006a): spatial scales of 1,2, 4 and $8 \mathrm{~km}$ and temporal scales of 10 , $30,60,180$ and $360 \mathrm{~min}$.

The AFs are then disaggregated with RainFARM producing $N$ equiprobable rainfall scenarios at the radar time and spatial resolution $(1 \mathrm{~km}, 10 \mathrm{~min})$ that are used to generate $N$ equiprobable streamflow scenarios by the Continuum model $(N=500)$.

For the sake of clarity we report the scheme of FFF in Fig. 4

We can state that the analysis is mainly made by the following steps:

1. aggregation of TRF on DV at fixed time and spatial scales (RS) obtaining AF

2. downscaling AF on radar spatial and temporal resolution with RainFARM obtaining $N$ equiprobable rainfall scenarios

3. using the $N$ equiprobable rainfall scenarios as input to Continuum to produce $N$ equiprobable streamflow scenarios.

\subsection{Hydraulic model: TELEMAC-MASCARET}

TELEMAC-MASCARET (http://www.opentelemac.org/) is an integrated suite of solvers for applications in the field of hydraulic modeling. It is managed by a consortium of core organizations. The suite contains different modules and in this work TELEMAC-2D is used. It solves the shallow water equations, also known as the Saint-Venant equations, using the finite-element or finite-volume method and a computation mesh of triangular elements. It can perform simulations in transient and permanent conditions. This software has many fields of application and is widely used for both research and technical purposes. In the maritime sphere, particular mention may be made of the sizing of port structures, the study of the effects of building submersible dikes or dredging, the impact of waste discharged from a coastal outfall, or the study of thermal plumes. In river applications, mention may also be made of studies relating to the impact of construction works (bridges, weirs, and tubes), dam breaks, flooding and transport of decaying or non-decaying tracers.

\subsection{Damage estimation}

Damage computation was carried out through the RASOR (Rapid Analysis and Spatialization Of Risk) platform (Rudari and the RASOR Team, 2015; Koudogbo et al., 2014), which enables multi-hazard risk analysis for full-cycle disaster management. RASOR integrates diverse data and products across hazards. It allows one to easily update exposure data and to make scenario-based predictions to support both short- and long-term risk-related decisions.

A conventional damage model, based on stage(m)damage (\%) vulnerability curves, was implemented to compute building damage related to each flood scenario. Damage assessment considers physical and economic damage to structures and their content.

Besides physical and economic damage, an estimation of the population potentially involved in the area was also given. A simple downscaling methodology was implemented to obtain population distribution at building scale in areas with different hazard levels.

\subsubsection{Exposure building}

Very detailed exposure data were obtained merging institutional information with Earth-observation-based (EO-based) and crowd-sourced geographic information and virtual surveys. Buildings were classified according to their occupancy class (usage), as required by the vulnerability model (see vulnerability paragraph below).

Official information from real estate registry and census (year 2011) was updated through high-resolution optical imagery and cross-compared with crowd-sourced datasets such as Open Street Map (http://www.openstreetmap.org). Inconsistencies found in the comparison of the two datasets were fixed thanks to field and virtual surveys.

Moreover, from real estate registry and census datasets it is impossible to distinguish between mixed-occupancy buildings. In fact, it is very common the case of buildings with commercial activities (shops, stores, banks, etc.) on the ground floor and dwelling on upper floors. In the same way, no information was provided on the presence of basement. While this type of information might play a minor role for other hazards, in case of flood it is relevant as it changes the response of the building in terms of damage. In this case, field and virtual surveys were realized to recognize these features and classify them in new building classes. The whole process led to an accurate description of the assets in the areas affected by the flood. The original occupancy classes 
Table 1. Original HAZUS building occupancy classes (normal font) and derived mixed-occupancy classes (bold).

\begin{tabular}{|c|c|c|}
\hline \multirow{2}{*}{$\begin{array}{l}\text { Label } \\
\text { RES1 }\end{array}$} & \multicolumn{2}{|l|}{ Occupancy class } \\
\hline & Single-family dwelling & Residential \\
\hline RES2 & Mobile home & \\
\hline RES3A & Multi-family dwelling - duplex & \\
\hline RES3B & Multi-family dwelling $-3-4$ units & \\
\hline RES3C & Multi-family dwelling $-5-9$ units & \\
\hline RES3D & Multi-family dwelling $-10-19$ units & \\
\hline RES3E & Multi-family dwelling - 20-49 units & \\
\hline RES3F & Multi-family dwelling $-50+$ units & \\
\hline RES4 & Temporary lodging & \\
\hline RES5 & Institutional dormitory & \\
\hline RES6 & Nursing home & \\
\hline COM1 & Retail trade & Commercial \\
\hline COM2 & Wholesale trade & \\
\hline COM3 & Personal and repair services & \\
\hline COM4 & Business/professional/technical services & \\
\hline COM5 & Depository institutions (e.g., bank) & \\
\hline COM6 & Hospital & \\
\hline COM7 & Medical office/clinic & \\
\hline COM8 & Entertainment \& recreation (e.g., restaurants and bar) & \\
\hline COM9 & Theaters & \\
\hline COM10 & Parking & \\
\hline IND1 & Heavy & Industrial \\
\hline IND2 & Light & \\
\hline IND3 & Food/drugs/chemicals & \\
\hline IND4 & Metal/mineral processing & \\
\hline IND5 & High technology & \\
\hline IND6 & Construction & \\
\hline AGR1 & Agriculture & Agriculture \\
\hline REL1 & Church/membership organization & Religion/non-profit \\
\hline GOV1 & General services & Government \\
\hline GOV2 & Emergency response & \\
\hline EDU1 & Schools/libraries & Education \\
\hline EDU2 & Colleges/universities & \\
\hline COM1 + RES & Residential with retail on ground floor & Mixed \\
\hline COM5 + RES & Residential with bank on ground floor & \\
\hline COM8 + RES & Restaurant and bar & \\
\hline
\end{tabular}

by HAZUS-MH database (www.fema.gov/hazus) distributed from FEMA (US Federal Emergency Management Agency, 2010) were extended as shown in Table 1.

\subsubsection{Exposure population}

Quantifying population exposure as a step for conducting spatially explicit risk assessment requires mapping the spatial distribution of population with adequate spatiotemporal resolution. Since natural hazards can affect urban areas in a very selective manner, only fine-scale population data can provide an accurate estimate of the affected population (Deichmann et al., 2011). Data on resident population (census tracts or global population data sources such as WorldPop - http://www.worldpop.org.uk/, Gridded Population of the World, and Global Rural-Urban Mapping Project by NASA, LandScan by UT-Battelle and United States Department of Energy) are not normally available at building scale. Moreover, due to its dynamic nature, the estimation of people presence in each building is quite complicated as it is affected by many variables, such as hour of the day, level of productivity in the area, main traffic patterns, etc.

In literature several methodologies are proposed to downscale population to fine scales. Some examples are choropleth method, areal interpolation method, dasymetric 
method, and statistical approach for population distribution in urban area (Bhaduri, et al., 2007; Holt et al., 2004; Langford et al., 2008; Wu et al., 2005; Freire, 2010).

In this study, a top-down approach is employed to spatially disaggregate and distribute the population from official census and statistics for nighttime and daytime periods, by adapting the methodology proposed by Freire and Aubrecht (2012).

Population is split into three classes: nighttime population (equal to the residential population), daytime residential population, and daytime worker and student population.

Total daytime population distribution results from the sum of the daytime population in their places of work or study and the population that remains at home during the day. The latter is obtained by multiplying the nighttime distribution by the ratio of resident population who, according to official statistics by the National Statistics Institute (ISTAT, 2011), does not commute to work or school. Daytime population is then distributed into buildings, which are considered the main aggregation places; a buffer around the building is considered to take into account also people which could be in the proximity of the building. Daytime residential population is then equally distributed among residential building storeys, while daytime commuting workers and students are distributed into non-residential building storeys.

\subsubsection{Vulnerability - building}

A classical damage model, based on stage(m)-damage(\%) vulnerability curves, was implemented to compute losses associated with each flood scenario. HAZUS-MH database provides one of the most complete collections of stagedamage curves. Water depth-damage functions in the HAZUS library are separately provided for structure (loadbearing systems, architectural, mechanical and electrical components, and building finishes) and for content. Different curves are available for different occupancy classes.

Starting from this collection, several curves were added to take into account additional classes such as mixed occupancy (e.g., retail trade and residential) and presence of basement (see Table 1). In order to create curves for mixed-occupancy and multiple-storey residential occupancy classes, the following procedure was applied. The first part (from 0 to $3 \mathrm{~m}$ ) of the residential curve for a one-floor building (RES1) from HAZUS is intended to be representative of each floor of a generic multi-story residential building. Under the assumption that each of the $N$ floors represents, in percentage of damage terms, $1 / N$ of the total building damage, for the construction of an $\mathrm{N}$-story residential building, it is necessary to sum this curve $N$ times, taking care to weigh each addend by multiplying by $1 / N$. The same hypothesis and the same procedure apply to mixed-type buildings with commercial activities on the first floor (retail trade or restaurant, etc.) and apartments on the other floors: in this case, for the first floor, the first part of the curves for commercial build-

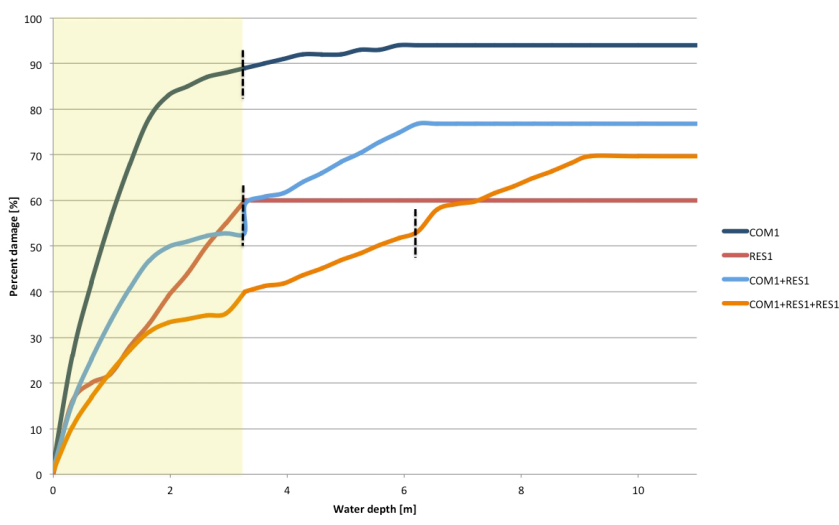

Figure 5. An example of mixed-use curve definition. The light blue curve corresponds to the flood vulnerability function for the content of a two-storey building, with mixed commercial and residential use: specifically retail trade on the ground floor and residential on the first floor. It is obtained by combining the one-storey curve for generic residential (in red) with the one-storey curve for retail trade (in blue). The yellow section of the graph represents the average height of the ground floor. The left part of the mixed curve is obtained by re-scaling the blue curve. For higher values of water level, the function increases proportionally to the values that the residential curves assume (red) in the left part of the graph. It is assumed that the value of the ground floor is equal to $60 \%$ of the whole (two-storey) building. The orange curve is built in an analogous way, considering a first commercial floor and two upper residential levels, obtained by adding two separate one-storey residential levels.

ing is used (e.g., COM1, COM8), while for each of the other floors the residential part of RES1 is summed $(N-1)$ times. In this case different weights for different occupancy types can be used, as in general the value for commercial floors is bigger than the one for residential floors.

Figure 5 shows a comparison between four water depthdamage curves for content: retail trade (COM1) building (blue), generic one-floor residential (RES1) building (red), mixed retail trade on the first floor and residential on the second floor (COM1 + RES1) building (light blue), and mixed retail trade on the first floor and residential on the second and third floors (COM1 + RES1 + RES1) building (orange).

Physical damage obtained by application of stage-damage functions can be transformed into economic losses (ED) using replacement cost per square meter.

$\mathrm{ED}[\mathrm{EUR}]=\mathrm{PD} \cdot A \cdot \mathrm{RC} \cdot(n+b)$,

where PD $(\%)$ is the physical damage, $A\left[\mathrm{~m}^{2}\right]$ is the area of the building footprint, $\mathrm{RC}\left[\frac{\mathrm{EUR}}{\mathrm{m}^{2}}\right]$ is the replacement cost per square meter, and $n$ is the number of floors

$b=\left\{\begin{array}{ll}0 & \text { if the building has no basement } \\ 1 & \text { if the building has a basement }\end{array}\right.$.

Two different lumped replacement costs are assigned for structure damage and content damage: 500 EUR m${ }^{-2}$ for 
structure replacement costs and $400 \mathrm{EUR} \mathrm{m}^{-2}$ for content replacement costs. Those costs were derived considering typical damage caused by flood (replacement of floor, doors and window fixtures, sewage and electric systems, finishes, plaster, etc.) and the local market prices indicated by the regional authority (Ministero delle Infrastrutture e dei Trasporti, 2014).

\subsubsection{Vulnerability - population}

Despite the enormous impacts of floods, there is relatively limited insight into the factors that determine the loss of life caused by flood events. In the literature several methods have been developed to assess the loss of lives due to flood events and to identify mitigation measures (DeKay and McClelland, 1993; Jonkman et al., 2008). In general these methods consist of a quantitative relationship between the flood characteristics (such as water depth, velocity) and the mortality in the flooded area.

In order to compare possible impacts on population for different scenarios, four hazard zones (very high, high, moderate, low flood hazard) were defined based on the human instability in floodwaters. In fact, practical experiments (Abt et al., 1989; Karvonen et al., 2000) show that in flow conditions $0.5<v<3 \mathrm{~m} \mathrm{~s}^{-1}$ and $0.3<h<1.5 \mathrm{~m}$ (where $v$ and $h$ are the velocity and the water level in the inundated street) the average human instability threshold in floodwaters corresponds to $h v=1.35 \mathrm{~m}^{2} \mathrm{~s}^{-1}$ (Jonkman et al., 2008). This is the threshold that differentiates the "high flood hazard" vs. "moderate flood hazard" zones. Further thresholds (upper and lower) were introduced based on "expert judgement" in order to identify two other classes: "very high flood hazard" (very high water level and velocity) and "low flood hazard" (low water level and velocity). The resulting four flood hazard zones can be ranked as follows:

- very high hazard zone when $h v \geq 5 \mathrm{~m}^{2} \mathrm{~s}^{-1}$ and $v \geq 2 \mathrm{~m} \mathrm{~s}^{-1}$

- high hazard zone when $h \geq 0.2 \mathrm{~m}$ and $h v>1.35 \mathrm{~m}^{2} \mathrm{~s}^{-1}$

- moderate hazard zone when $(h<0.2 \mathrm{~m}$ and $\left.h v>1.35 \mathrm{~m}^{2} \mathrm{~s}^{-1}\right)$ or $(0.5>\mathrm{h} \geq 0.2 \mathrm{~m}$ and $v>1$ and $\left.h v<1.35 \mathrm{~m}^{2} \mathrm{~s}^{-1}\right)$ or $\left(h>0.5 \mathrm{~m}\right.$ and $\left.h v<1.35 \mathrm{~m}^{2} \mathrm{~s}^{-1}\right)$

- low hazard zone when $\left(h<0.2 \mathrm{~m}\right.$ and $\left.h v<1.35 \mathrm{~m}^{2} \mathrm{~s}^{-1}\right)$ or $\left(0.5>\mathrm{h} \geq 0.2 \mathrm{~m}\right.$ and $v<1 \mathrm{~m} \mathrm{~s}^{-1}$.

For each zone potentially affected, population is computed taking into account where the population is located during the day and the night at building level. This method can give useful indications especially in relative terms when comparing different scenarios.

\section{Results}

\section{1 $\quad$ FFF}

The results are shown using box plot representation. Figure 6 shows the box plot of the 500 peak flows generated with FFF compared with the mean peak flow of the sample of 500 realizations represented by the blue diamonds for the reference model section on Bisagno creek. Each panel refers to a different spatial RS (RSs), while on the $x$ axis the temporal RS (RSt) is reported (the case with $\mathrm{RSs}=1 \mathrm{~km}$ and $\mathrm{RSt}=10 \mathrm{~min}$ is obviously not considered since it corresponds to the resolution of the original field).

It is noticeable the fact that the $Q_{p}$ varies from 1200 to $1800 \mathrm{~m}^{3} \mathrm{~s}^{-1}$ considering the 25 th and 75 th percentile of the box especially for spatial aggregations RSs 1 and $2 \mathrm{~km}$, while the mean $Q_{p}$ is between 1400 and $1600 \mathrm{~m}^{3} \mathrm{~s}^{-1}$. This means that the considered rainfall field could lead to a peak flow with a return period $T$ larger than 200 years, $Q\left(T=200\right.$ years) $\cong 1300 \mathrm{~m}^{3} \mathrm{~s}^{-1}$ (Boni et al., 2007; Provincial Authority of Genoa, 2001). Just to have some terms of comparison, the 4 November 2011 flood led to a peak flow around $750-800 \mathrm{~m}^{3} \mathrm{~s}^{-1}$ (Silvestro et al., 2012), and the 9 October 2014 major flood (Silvestro et al., 2015b) led to a peak flow around $1100-1200 \mathrm{~m}^{3} \mathrm{~s}^{-1}$. The peak flow of the flood on 7 October 1970 was estimated at around $1100 \mathrm{~m}^{3} \mathrm{~s}^{-1}$ (Rosso, 2014).

We considered the configuration with $\mathrm{RSs}=4 \mathrm{~km}$ and $\mathrm{RSt}=3 \mathrm{~h}$ in order to account for spatial and temporal uncertainty of rainfall pattern and to give a certain variability to the disaggregated rainfall fields, and to maintain a certain spatiotemporal coherence between RSs and RSt (Rebora et al., 2006b); we extracted the hydrographs that lead to the peak flows with 10th, 25th, 50th, 75th, and 90th percentiles (hereafter perc10 to perc90), as they are reported in Fig. 7.

The time series furnish important information. Firstly they confirm the severity of the possible streamflow scenarios (consider that given the current structural condition of the riverbed the flooding threshold is around $700 \mathrm{~m}^{3} \mathrm{~s}^{-1}$ ); secondly they evidence that the flooding would have occurred between 12:00 and 16:00 UTC (14:00-18:00 local time - LT) when the potential risk for human lives and goods was very high. In fact during that time window the city is in full activity: there is a lot of traffic due to people that use means of transport for work, the shops and stores are open, and children exit from school.

\subsection{Hydraulic model validation}

The extent of hazard map was estimated using the hydraulic model TELEMAC-2D. The basic static input data used by TELEMAC-2D are from a digital elevation model (DEM). In this application a DEM with $1 \mathrm{~m}$ spatial resolution acquired by light detection and ranging (lidar) technology was used; DEM information was integrated with a detailed description 

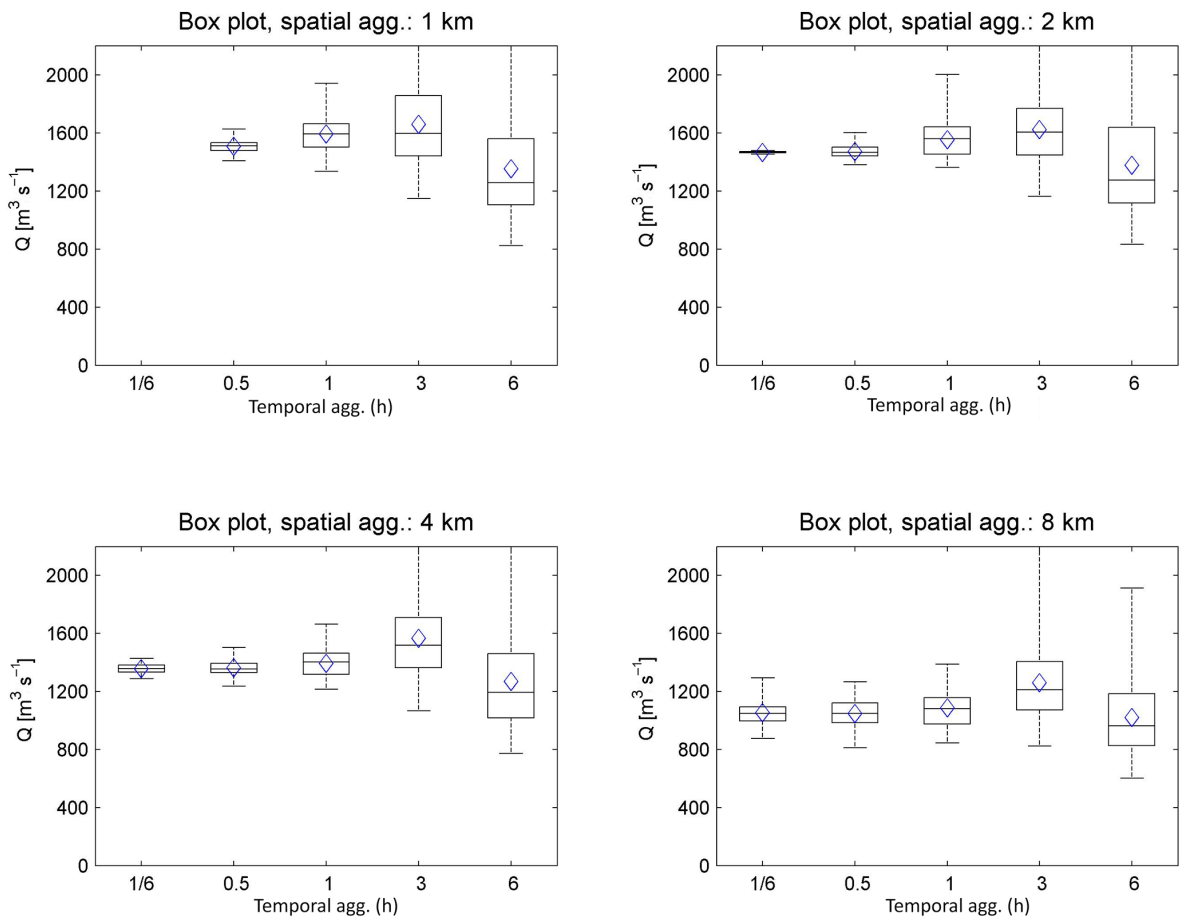

Figure 6. Passerella Firpo reference section, area: $93 \mathrm{~km}^{2}$. Box plot of the peak flow generated by the FFF. On $y$ axis the peak flow is reported; on $x$ axis the temporal aggregation scales (RSt) are reported. Diamonds represent the peak flow of the reference hydrograph. Each subpanel shows results for a different spatial aggregation scale (RSs).

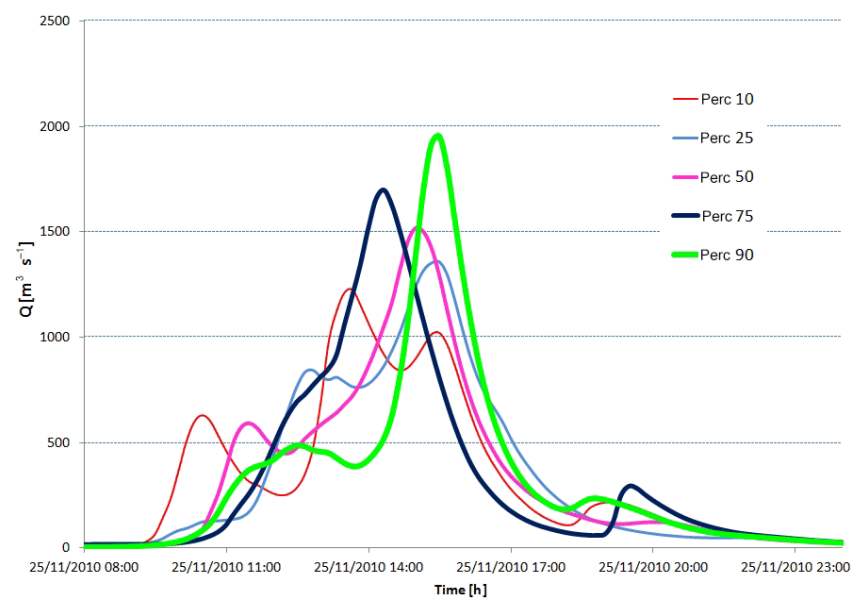

Figure 7. Streamflow scenarios derived by $\mathrm{RSs}=4 \mathrm{~km}$ and $\mathrm{RSt}=3 \mathrm{~h}$. The hydrographs that lead to the peak flows with $10 \mathrm{th}$, 25th, 50th, 75th, and 90th percentiles were extracted.

of the Bisagno riverbed derived by survey measurements carried out between August 2012 and June 2013. The aforementioned data were used to describe the topology of the area of the city of Genoa affected by the Bisagno creek flooding events. The hydraulic model was set and calibrated to reproduce historical flooding, especially the one that occurred 9 October 2014 (Silvestro et al., 2015b). For the latter a lot of data are in fact available together with a large number of field measurements that allowed the good estimation of the magnitude of the flood in terms of both water level and extent (Fig. 8).

The final setting of the model allows a good reproduction of the field post-event measurements. Some mismatches are present and they are due to a non-perfect reproduction of the real altitudes by the DEM in some areas, and by the fact that some features (for example basements) cannot be described with high detail but only in a parametric way.

\subsection{Hazard mapping and damage estimation}

This exposure dataset and the entire damage computation methodology presented in Sect. 3.3 were validated referring to a recent urban flash flood, which occurred on 9 October 2014 in Genoa (Silvestro et al., 2015b). During this event hazard and exposure-vulnerability models were computed separately and validated against observations and claims. As shown in Sect. 4.2 the maximum water depth values obtained by the hydraulic model were compared and validated with flood marks collected in the aftermath of the flood as described in Sect. 4.2 (Fig. 8). The total simulated damage was then compared and validated across the official damage assessment obtained through citizen claims and municipal authorities surveys (Trasforini et al., 2015). In that study, over 3000 refund requests for flood damage were processed 


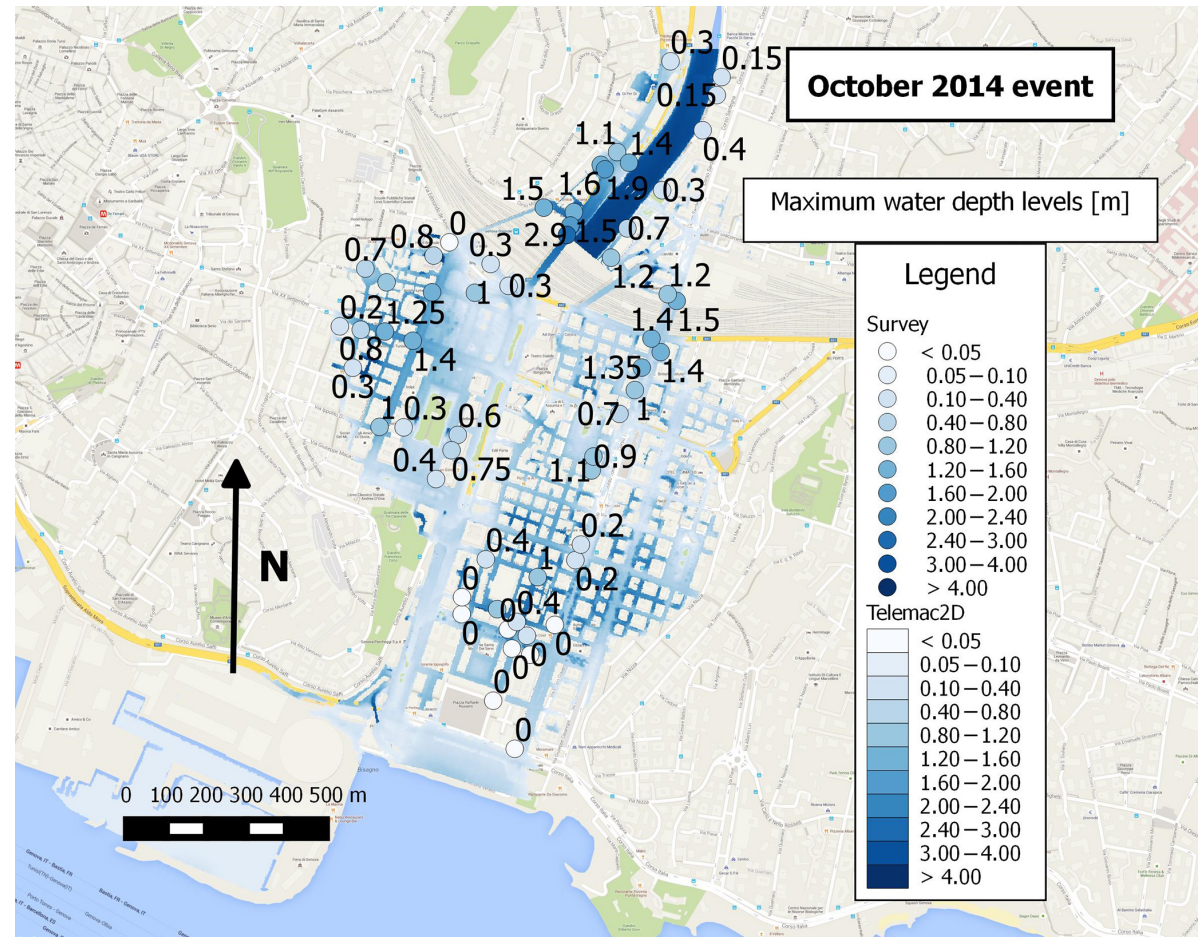

Figure 8. Center of the city of Genoa. Flood occurred on 9 October 2014. Comparison of the maximum flooding extent obtained through TELEMAC-2D and the field observations. The model was set in order to obtain the best fit between modeling and observations.

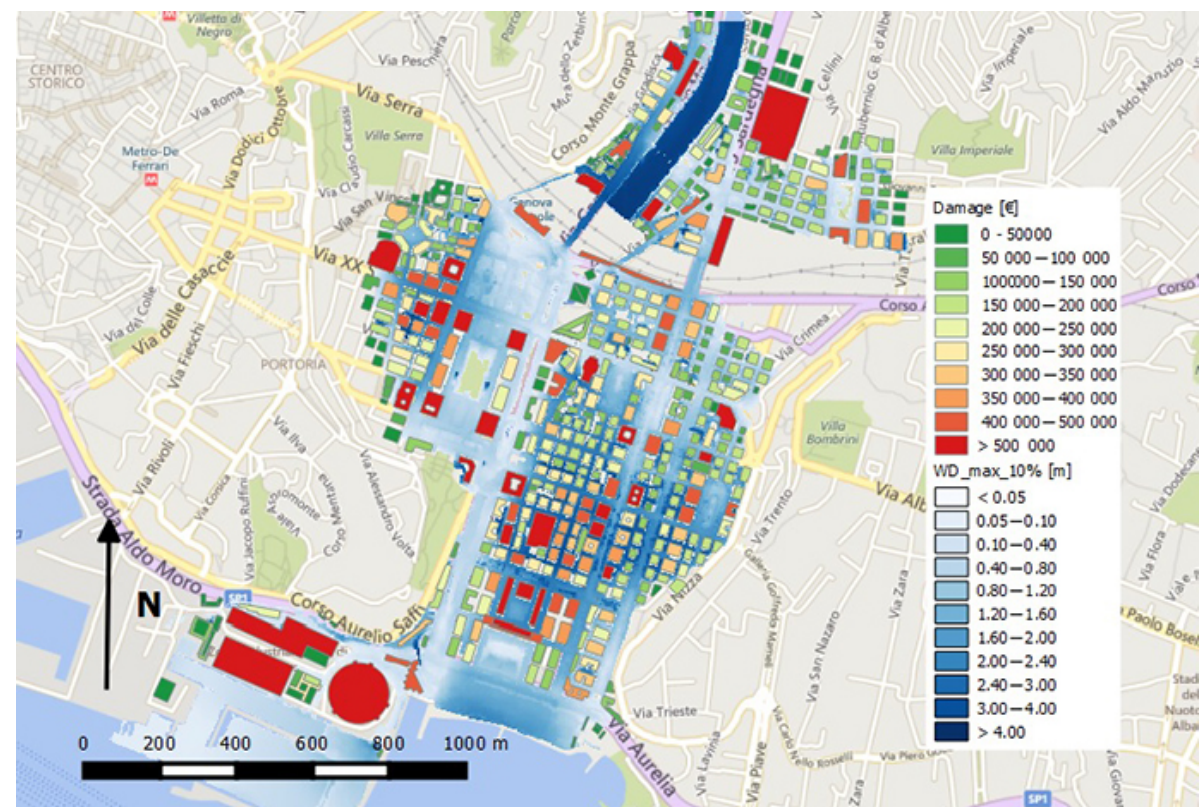

Figure 9. Perc10 scenario, inundation map and damage estimation. In blue scale the water level is reported. The damage is estimated at building scale in EUR; the color scale ranges from low damage (green) to high damage (red).

and georeferenced, aggregated at building and neighborhood scale to validate computed losses.

It must be remarked that damage to building structure and content does not represent the whole damage reported dur- ing the event. A relevant portion of total damage was due to cars parked in private and public parking and along the streets, transport facilities (roads and train station), and pub- 


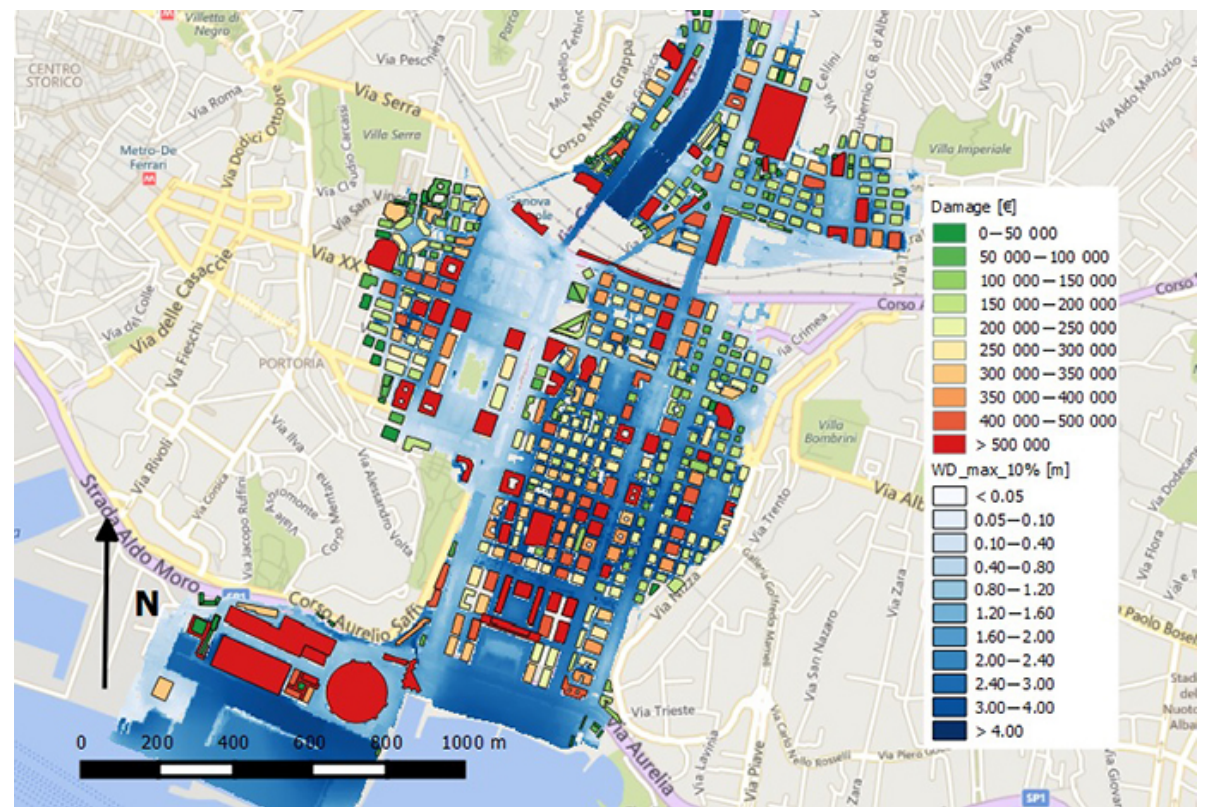

Figure 10. Perc50 scenario, inundation map and damage estimation. In blue scale the water level is reported. The damage is estimated at building scale in EUR; the color scale ranges from low damage (green) to high damage (red).

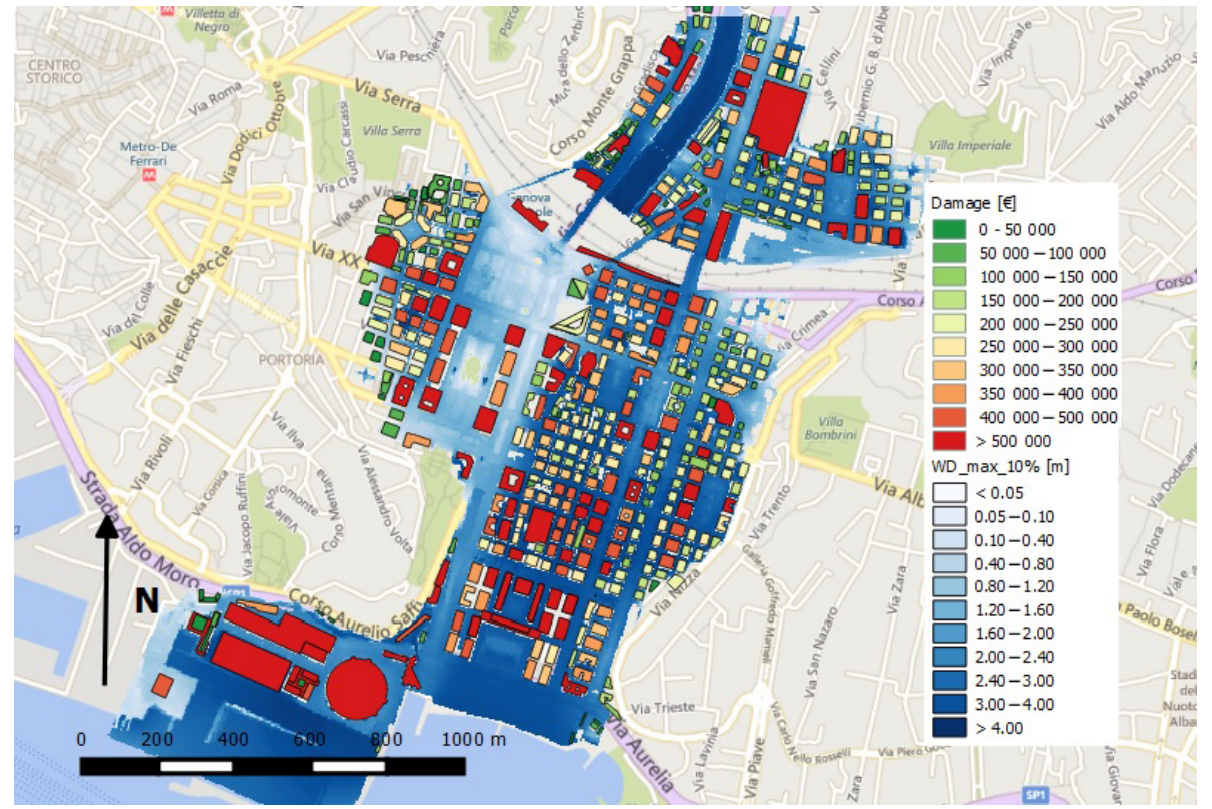

Figure 11. Perc90 scenario, inundation map and damage estimation. In blue scale the water level is reported. The damage is estimated at building scale in EUR; the color scale ranges from low damage (green) to high damage (red).

lic sewage systems. These contributions are not accounted for in the presented analysis.

The five streamflow scenarios identified in Sect. 4.1 (scenarios perc10 to perc90) were used as input to TELEMAC$2 \mathrm{D}$ and then the methodologies described in Sect. 3.3 were applied to estimate the damage and the affected population.
An important hypothesis that was formulated and that needs to be noticed is related to the point where the flooding starts along the riverbed. It is in fact assumed to be constant for all the scenarios and coincident with the flooding point that occurred during the benchmark event (9 October 2014 flash flood) used for validation. This is not rigorously correct, but we needed to make this assumption for different 


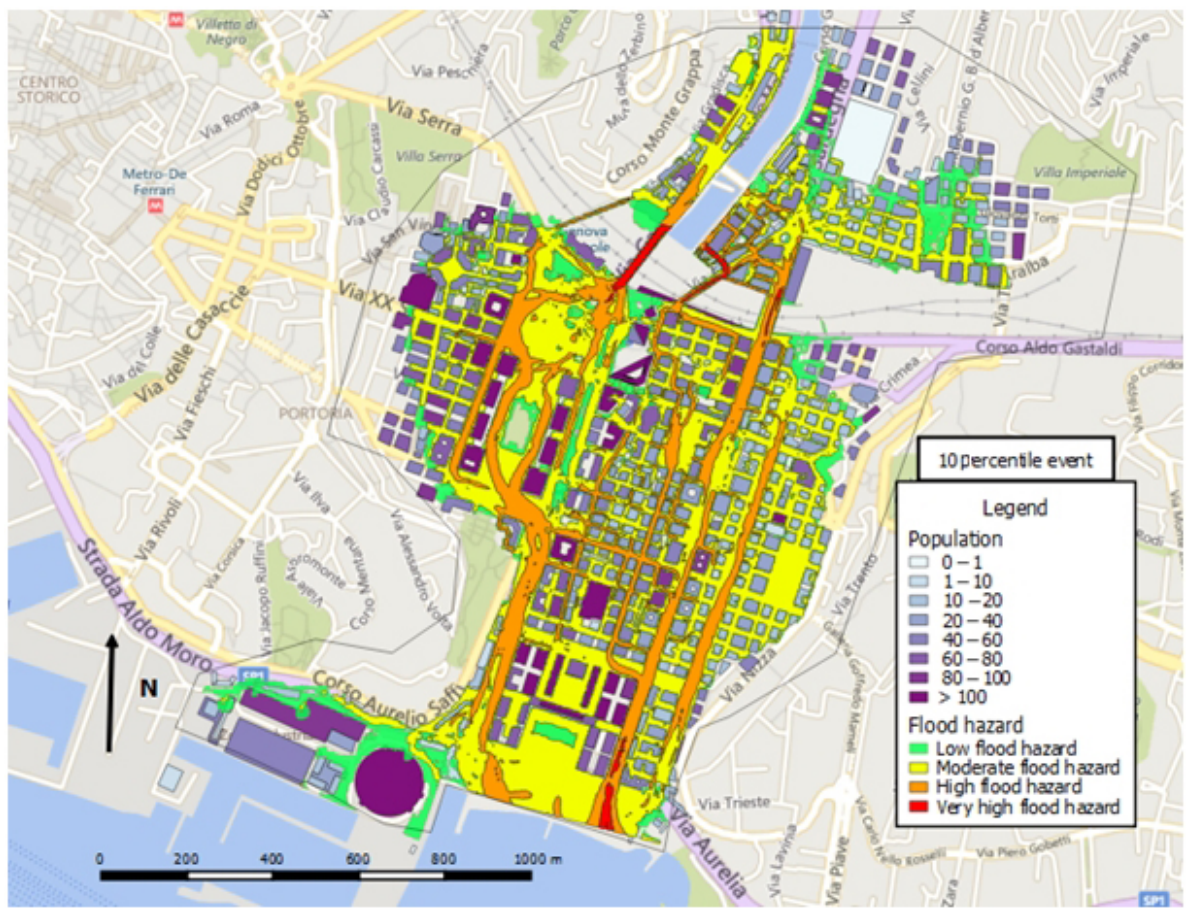

Figure 12. Perc10 scenario, hazard level map compared with population potentially involved assigned to each building.

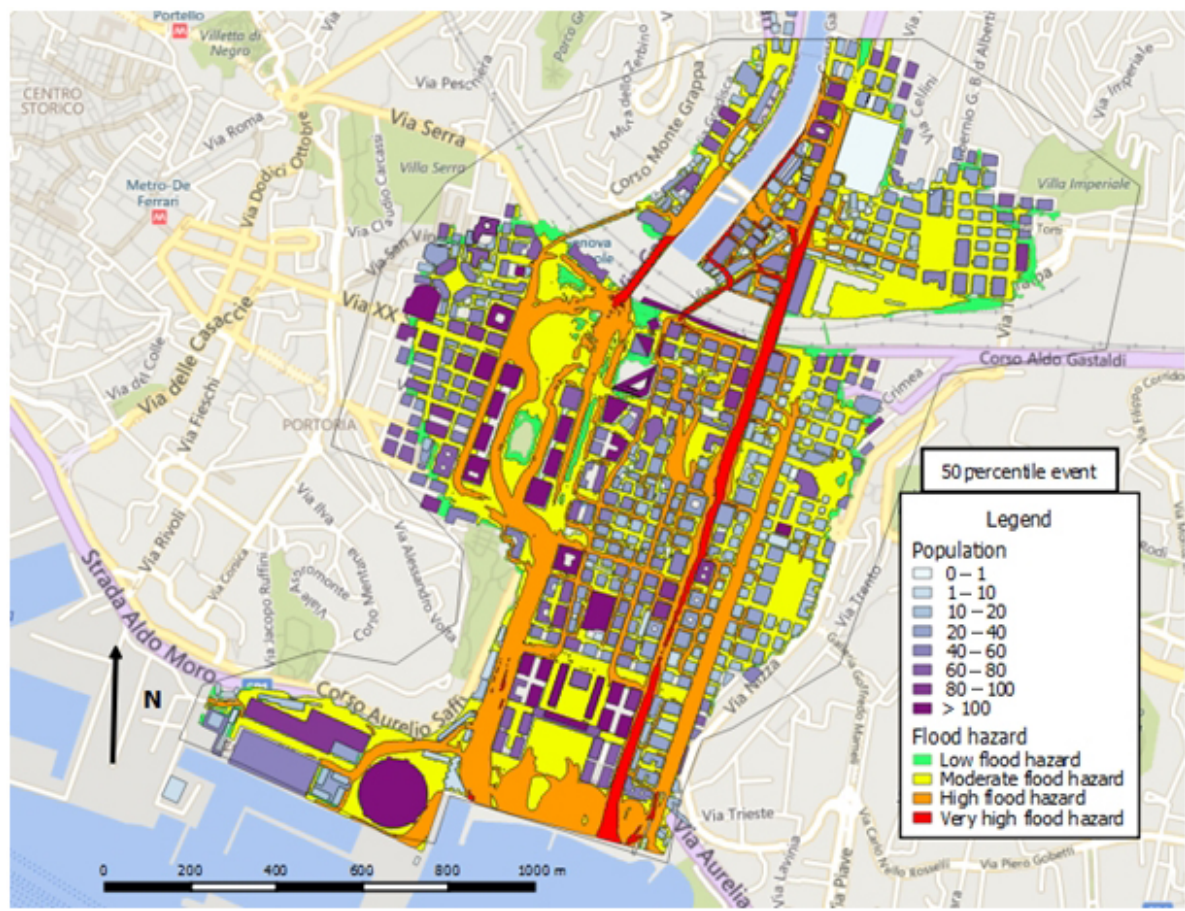

Figure 13. Perc50 scenario, hazard level map compared with population potentially involved assigned to each building.

reasons. Particularly binding was the fact that some information was available only for the considered area. We refer to the high-resolution DEM and to some data needed to carry out the damage estimation. All this leads to an underestima- tion of the total flooding area because the areas near the river branch upstream of the considered point are not accounted for. 


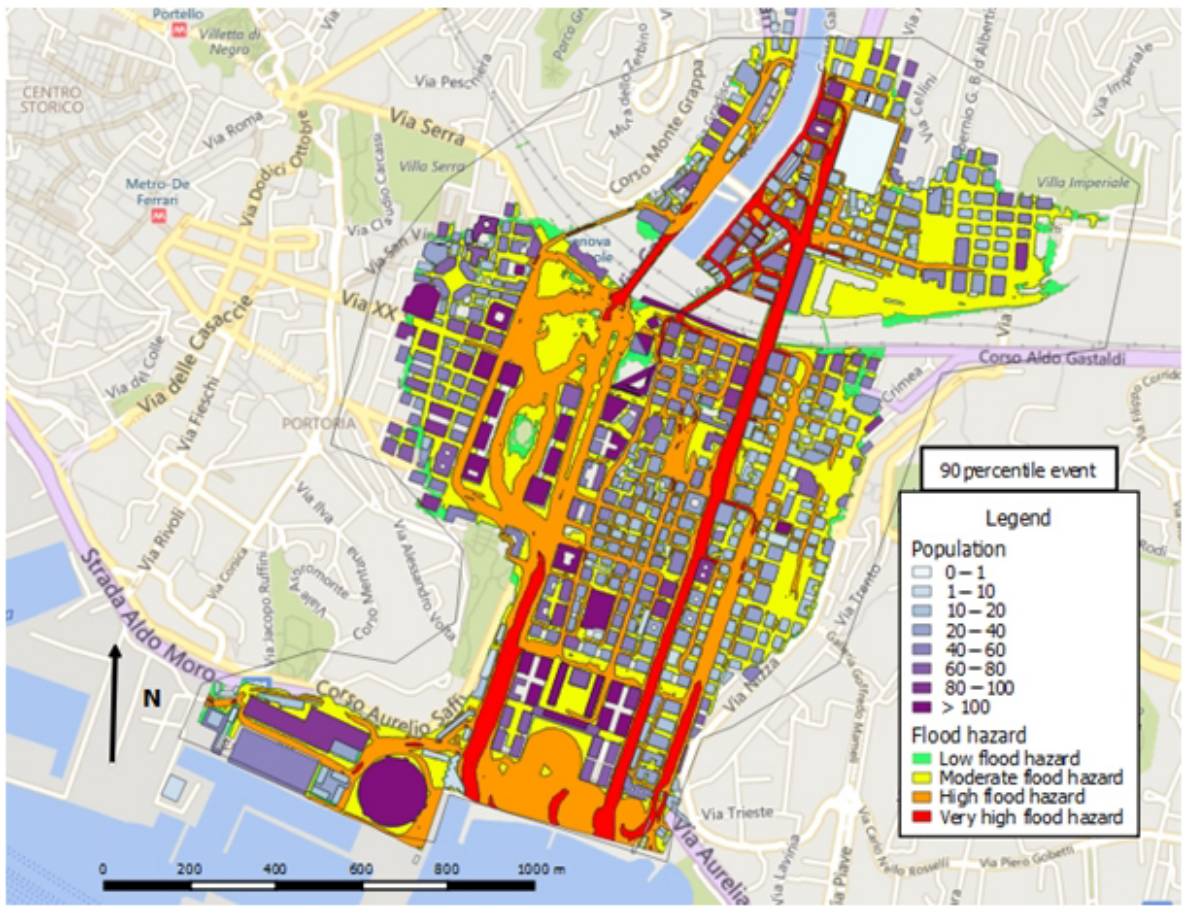

Figure 14. Perc90 scenario, hazard level map compared with population potentially involved assigned to each building.

The results are presented in Figs. 9-11, where hazard maps are shown together with economic damage at building scale.

As can be easily seen the flooding affects a large heavily urbanized area, where several stores, offices, retail trade activities, schools and residential buildings are placed. The extent of the affected area weakly changes between perc10 to perc 90 scenarios because of the topology of the city; anyway the water level in various areas changes dramatically with increases of even $2-3 \mathrm{~m}$. This is due to the increase of flooding volumes and their accumulation on the depressed areas. This occurrence clearly leads to a different impact in terms of damage to goods and to a different level of risk for the lives of citizens.

In Tables 2 and 3 the estimation of economic damage is reported for each flooding scenario compared with the damage estimated for the 9 October 2014 flash flood, used as a benchmark, during which a peak flow that corresponds to a $100<T<200$ years was registered. Results are reported both as absolute values and percentage values and separating the damage to the structures from damage to the content. It is impressive that the total damage for the simulated events ranges about EUR 141-232 million, which in percent means a range between 140 and $231 \%$ of the 2014 event. Even the Perc10 scenario leads to a larger amount of damages with respect to the benchmark event notwithstanding the peak flows are comparable; this is probably due by a larger overbanking volume.

Table 4 reports the total affected population and their distribution in the areas at different levels of risk. Population was distributed according to a daytime scenario (the hypothetical event would have occurred between 14:00 and 18:00 LT), considering that people can be found not only in dwellings but also in commercial and industrial buildings, schools, etc. (see Sect. 3.3.2).

Figures 12 to 14 show the maps with zones at different hazard levels together with the affected population assigned to each building, while Table 4 reports the total affected population and its distribution in zones with different levels of hazard.

The total population that can be potentially affected by flooding is quite high (almost 19000 people) and does not significantly change from one scenario to another. This is due to the fact that the extension of the inundated area does not change significantly because of the topology. Clearly the percentage of people that can found themselves in areas at high or very high level of risk increases with the hazardousness of the scenarios (from perc10 to perc90) because of the different water levels and different flow velocities. This fact is evidenced both by Figs. 12-14 and by the Table 4 .

\section{Discussion and conclusion}

The presented work analyses the consequences of a hypothetical but realistic event in the city of Genoa located at the mouth of Bisagno creek, Liguria Region, Italy. This approach aims at quantifying impacts of possible real events in a "worst-case" perspective. This is accomplished considering the rainfall field occurred during a real flash flood event 
Table 2. Economic damage estimated for the considered flooding scenarios compared with damage estimated for the event on 9 October 2014.

\begin{tabular}{lllllll}
\hline & Perc10 & Perc25 & Perc50 & Perc75 & Perc90 & 2014 event \\
\hline Economic damage to structures (million EUR) & 42.7 & 53.7 & 59.3 & 67.3 & 73.6 & 29.7 \\
Economic damage to content (million EUR) & 97.9 & 121.9 & 134.5 & 148.6 & 158 & 70.4 \\
Total damage (million EUR) & 140.6 & 175.6 & 193.8 & 211.9 & 231.6 & 100.1 \\
\hline
\end{tabular}

Table 3. Ratio between damage estimated for the considered flooding scenarios and damage estimated for the event on 9 October 2014 .

\begin{tabular}{lllllll}
\hline & Perc10 & Perc25 & Perc50 & Perc75 & Perc90 & 2014 event \\
\hline Economic damage to structure caused by the 2014 event & $144 \%$ & $181 \%$ & $200 \%$ & $227 \%$ & $248 \%$ & $100 \%$ \\
Economic damage to content caused by the 2014 event & $139 \%$ & $173 \%$ & $191 \%$ & $212 \%$ & $224 \%$ & $100 \%$ \\
Total economic damage caused by the 2014 event & $140 \%$ & $175 \%$ & $194 \%$ & $212 \%$ & $231 \%$ & $100 \%$ \\
\hline
\end{tabular}

at about $50 \mathrm{~km}$ of distance and transferring it over the target catchment following a robust and novel methodology based on the work presented in Silvestro et al. (2015b). The motivations that drove this kind of analysis can be found various papers (Buzzi et al., 2014; Delrieu et al., 2006; Rebora et al., 2013; Silvestro et al., 2012, 2015b) which show that this kind of very intense rainfall structures can potentially strike, more or less indifferently, a large portion of the coastal Liguria Region.

The rainfall field was used as input to a flood forecast framework made by a downscaling model and a hydrological model in order to account for uncertainties related to the spatial and temporal structure of the rainfall pattern and to generate an ensemble of possible streamflow scenarios; a subset of these streamflow scenarios was then used to feed a hydraulic model in order to simulate the hazard maps. The latter are then used to estimate the damages with a proper methodology developed within the RASOR FP7 project (Rudari and the RASOR Team, 2015; Koudogbo et al., 2014).

The results of the experiments can be summarized as follows:

1. The hypothetical rainfall event led to a very lowfrequency and extreme flood event near Bisagno creek. The peak flow at the section Passerella Firpo (located in the city of Genoa) is around $1400-1600 \mathrm{~m}^{3} \mathrm{~s}^{-1}$, which corresponds to a return period $T$ larger than 200 years.

2. Peak flows of the aforementioned magnitudes are realistic and possible even if in living memory they never occurred. This is not a commonplace result. In fact, generally, these high flow values $(T>200$ years $)$ are the result of statistical analysis of observed/simulated annual maxima time series with reduced length $N$ (with $N<50-100$ values), so they are very uncertain. The experiment generates such streamflow magnitude using a real rainfall event and considering a realistic soil moisture as the initial condition of the study area.
3. The flooding of Bisagno creek in the city of Genoa leads to a large inundation area with water level even higher than $2-3 \mathrm{~m}$ in the center of the city. The large volume of flooding produces large accumulation in the streets especially in depressed areas.

4. Overbanking occurs between 12:00 and 16:00 UTC (14:00 to $18: 00 \mathrm{LT}$ ), which is a really dangerous time window with a large number of people that can be potentially affected by the inundation.

5. The estimated damage to the structures and their content is EUR 141-232 million, 140 to $231 \%$ of the benchmark event, which was caused by a peak flow with 100 years $<T<200$ years.

6. The population potentially affected is roughly between 17000 and 19000 units, with a distribution in the areas at high and very high hazard level, which ranges between 3600 and 7700 units. This is a conservative estimate since the applied methodology does not completely account for people that live out of the affected area but can access the area during their daytime activities.

These results show how devastating an event of such a magnitude could be, and they highlight the need for augmenting the resilience of the city and its population. Sophisticated and state-of-the-art early warning systems (EWSs) as well as nowcasting techniques (Silvestro et al., 2011; Berenguer et al., 2005) are already operational in the study area as well a civil protection system that is able to act on the territory (Brandolini et al., 2012). However, we have to consider that EWSs can fail especially in the exact localization of the event (Silvestro et al., 2015b; Buzzi et al., 2014) and that a civil protection system is effective when the population is able to react to the alert and warning messages with tangible behaviors and actions. The preparedness and correct information of the population is a basic prerequi- 
Table 4. Population potentially affected by the different flooding scenarios and their distribution on the zones with different levels of risk. The total is estimated summing the population of the low, moderate, high and very high risk zones.

\begin{tabular}{llllll}
\hline Scenario & $\begin{array}{l}\text { Total } \\
\text { (no. of people affected) }\end{array}$ & $\begin{array}{l}\text { Low hazard } \\
\text { (no. of people affected) }\end{array}$ & $\begin{array}{l}\text { Moderate hazard } \\
\text { (no. of people affected) }\end{array}$ & $\begin{array}{l}\text { High hazard } \\
\text { (no. of people affected) }\end{array}$ & $\begin{array}{l}\text { Very high hazard } \\
\text { (no. of people affected) }\end{array}$ \\
\hline Perc10 & 17360 & 3085 & 10705 & 3520 & 50 \\
Perc25 & 18255 & 2390 & 11175 & 4400 & 290 \\
Perc50 & 18440 & 2140 & 10475 & 5195 & 630 \\
Perc75 & 18645 & 1975 & 10005 & 5675 & 990 \\
Perc90 & 18805 & 1890 & 9205 & 6360 & 1350 \\
\hline
\end{tabular}

site to save lives and try to reduce the loss of goods: people (especially those who live or work in areas at high risk) should know exactly how to behave in case of an event and avoid such actions that increase their risk. Moreover, even if in the case of a (purely hypothetical) perfect EWS, which would enable civil protection to issue prompt alert messages and to save the entire population, the level of damage would be huge anyway, causing large problems to the economy of city. In this regard, a retrofitting measure aimed to reduce vulnerability (i.e., some small investments such as rails for stop logs) can be useful in order to reduce the damages, especially in those areas where water level does not reach very high values. These interventions can be really effective until structural measures are completed, and they can be useful to manage the residual risk once structural interventions have been carried out. In the specific case, a series of structural measures designed to avoid flooding driven by peak flows with $T \leq 200$ years are planned for the next years. (http://www.pianidibacino.ambienteinliguria. it/GE/bisagno/documenti/PianoInterventi.pdf).

Acknowledgements. This work is supported by the RASOR Project (founded by the European Union's Seventh Framework Programme for research, technological development and demonstration under grant agreement no. 606888), by the Italian National Civil Protection Department and by the Italian Region of Liguria.

Edited by: B. Merz

Reviewed by: M. C. Llasat and G. Pegram

\section{References}

Abt, S. R., Wittler, R. J., Taylor, A., and Love, D. J.: Human stability in a high flood hazard zone, Water Resour. Bull., 25, 881-890, 1989.

Alfieri, L., Thielen, J., and Pappenberger, F. L.: Ensemble hydro-meteorological simulation for flash flood early detection in southern Switzerland, J. Hydrol., 424-425, 143-153, doi:10.1016/j.jhydrol.2011.12.038, 2012.

Amengual, A., Romero, R., Gomez. M., Martın. A., and Alonso, S.: A hydrometeorological modeling study of a flash-flood event over Catalonia, Spain, J. Hydrometeorol., 8, 282-303, 2007.
Barthlott, C. and Kirshbaum, D. J.: Sensitivity of deep convection to terrain forcing over Mediterranean islands, Q. J. Roy. Meteor. Soc., 139, 1762-1779, 2013.

Berenguer, M., Corral, C., Sanchez-Diesma, R., and SempereTorres, D.: Hydrological validation of a radar-based nowcasting technique, J. Hydro-Meteorol., 6, 532-549, 2005.

Bhaduri, B.: Population Distribution During the Day, edited by: Shekhar, S. and Xiong, H., Encyclopedia of GIS, New York, USA, Springer, 880-885, 2007.

Boni, G., Ferraris, L., Giannoni, F., Roth, G., and Rudari, R.: Flood probability analysis for un-gauged watersheds by means of a simple distributed hydrologic model, Adv. Water Resour., 30, 2135 2144, doi:10.1016/j.advwatres.2006.08.009, 2007.

Borga, M., Anagnostou, E. N., Blöschl, G., and Creutin, J. D.: Flash flood forecasting, warning and risk management: the HYDRATE project, Environ. Sci. Policy, 834-844, 2011.

Brandolini, P., Cevasco, A., Firpo, M., Robbiano, A., and Sacchini, A.: Geo-hydrological risk management for civil protection purposes in the urban area of Genoa (Liguria, NW Italy), Nat. Hazards Earth Syst. Sci., 12, 943-959, doi:10.5194/nhess-12-9432012, 2012.

Buzzi, A., Davolio, S., Malguzzi, P., Drofa, O., and Mastrangelo, D.: Heavy rainfall episodes over Liguria in autumn 2011: numerical forecasting experiments, Nat. Hazards Earth Syst. Sci., 14, 1325-1340, doi:10.5194/nhess-14-1325-2014, 2014.

Davolio, S., Silvestro., F., and Malguzzi, P.: Effects of Increasing Horizontal Resolution in a Convection Permitting Model on Flood Forecasting: The 2011 Dramatic Events in Liguria (Italy), J. Hydrometeorol., 16, 1843-1856, doi:10.1175/JHM-D14-0094.1, 2015.

DeKay, M. L. and McClelland, G. H.: Predicting loss of life in cases of dam failure and flash flood, Risk Anal., 13, 193-205, 1993.

Deichmann, U., Ehrlich, D., Small, C., and Zeug, G.: Using high resolution satellite data for identification of urban natural risk, European Union and World Bank, 32-33, 2011.

Delrieu, G., Ducrocq, V., Gaume, E., Nicol, J., Payrastre, O., Yates, E., Kirstetter, P.E. , Andrieu, H., Ayral, P.-A., Bouvier, C., Creutin, J.-D., Livet, M., Anquetin, S., Lang, M., Neppel, L., Obled, C., Parent-du-Châtelet, J., Saulnier, G. M., Walpersdorf, A., and Wobrock, W.: The catastrophic flash-flood event of 8-9 September 2002 in the Gard Region, France: a first case study for the Cévennes-Vivarais Mediterranean Hydrometeorological Observatory, J. Hydrometeorol., 6, 34-52, 2006.

FEMA Dept. of Homeland Security, Mitigation Division, Hazus ${ }^{\circledR}$ MH Technical Manual, 2010.

Fiori, E., Comellas, A., Molini, L., Rebora, N., Siccardi, F., Gochis, D. J., Tanelli, S., and Parodi, A.: Analysis and hindcast simula- 
tions of an extreme rainfall event in the Mediterranean area: The Genoa 2011 case, Atmos. Res., 138, 13-29, 2014.

Freire, S.: Modeling of Spatiotemporal Distribution of Urban Population at High Resolution - Value for Risk Assessment and Emergency Management, edited by: Konecny, M., Zlatanova, S., and Bandrova, T. L., Geographic Information and Cartography for Risk and Crisis Management, 53-67, Berlin Heidelberg, Springer, 2010.

Freire, S. and Aubrecht, C.: Integrating population dynamics into mapping human exposure to seismic hazard, Nat. Hazards Earth Syst. Sci., 12, 3533-3543, doi:10.5194/nhess-12-3533-2012, 2012.

Gaume, E. and Borga, M.: Post-flood field investigations in upland catchments after major flash floods: proposal of a methodology and illustrations, J. Flood Risk Manag., 1, 175-189, 2008.

Gaume, E., Bain, V., Bernardara, P., Newinger, O., Barbuc, M., Bateman, A., Blaskovicova, L., Blöschl, G., Borga, M., Dumitrescu, A., Daliakopoulos, I., Garcia, J., Irimescu, A., Kohnova, S., Koutroulis, A., Marchi, L., Matreata, S., Medina, V., Preciso, E., Sempere-Torres, D., Stancalie, G., Szolgay, J., Tsanis, I., Velasco, D., and Viglione, A.: A compilation of data on European flash floods, J. Hydrol. 367, 70-78, 2009.

Holt, J. B., Lo, C. P., and Hodler, T. W.: Dasymetric estimation of population density and areal interpolation of census data, Cartogr. Geograph. Inf. Sci., 31, 103-121, doi:10.1559/1523040041649407, 2004.

Jonkman, S. N., Vrijling, J. K., and Vrouwenvelder, A. C. W. M.: Methods for the estimation of loss of life due to floods: A literature re-view and a proposal for a new method, Nat. Hazards, 46, 353-389, 2008.

Karvonen, R. A., Hepojoki, H. K., Huhta, H. K., and Louhio, A.: The use of physical models in dam-break analysis. RESCDAM Final Report, p. 9, Helsinki University of Technology, Helsinki, Finland, 2000.

Koudogbo, F. N., Duro J., Rossi, L., Rudari, R., and Eddy, A.: Multi-hazard risk analysis using the FP7 RASOR Platform, Proc. SPIE, XVI, 92390J, doi:10.1117/12.2067444, 2014.

ISTAT - Istituto Nazione di Statistica, Censimento della popolazione, available at: http://www.istat.it/en/archive/ population-and-households (last access January 2016), 2011.

Laiolo, P., Gabellani, S., Rebora, N., Rudari, R., Ferraris, L., Ratto, S., Stevenin, H., and Cauduro, M.: Validation of the FloodPROOFS probabilistic forecasting system, Hydrol. Process., 28, 3466-3481, doi:10.1002/hyp.9888, 2014.

Langford, M., Higgs, G., Radcliffe, J., and White, S.: Urban population distribution models and service accessibility estimation, Comput. Environ. Urban, 32, 66-80, doi:10.1016/j.compenvurbsys.2007.06.001, 2008.

Liechti, K., Panziera, L., Germann, U., and Zappa, M.: The potential of radar-based ensemble forecasts for flash-flood early warning in the southern Swiss Alps, Hydrol. Earth Syst. Sci., 17, 38533869, doi:10.5194/hess-17-3853-2013, 2013.

Marchi, L., Borga, M., Preciso, E., Sangati, M., Gaume, E., Bain, V., Delrieu, G., Bonnifait, L., and Pogancik, N.: Comprehensive post-event survey of a flash flood in Western Slovenia: observation strategy and lessons learned, Hydrol. Process., 23, 37613770, doi:10.1002/hyp.7542, 2009.
Massacand, A. C., Wernli, H., and Davies, H. C.: Heavy precipitation on the alpine southside: an upper level precursor, Geophys. Res. Lett., 25, 1435-1438, 1998.

Ministero delle Infrastrutture e dei Trasporti, Provveditorato Regionale per le O.O.P.P. per la Lombardia e la Liguria, Prezzario Regionale Opere edili/impiantistica, Prezzi medi e informativi, 2014, edited by:. Unioncamere Liguria, Genova, 2014.

Molini, L., Parodi, A., and Siccardi, F.: Dealing with uncertainty: an analysis of the severe weather events over Italy in 2006, Nat. Hazards Earth Syst. Sci., 9, 1775-1786, doi:10.5194/nhess-91775-2009, 2009.

Nardi, L. and Rinaldi, M.: Spatio-temporal patterns of channel changes in response to a major flood event: the case of the Magra River (central-northern Italy), Earth Surf. Process. Landf., 40, 326-339, doi:10.1002/esp.3636, 2014.

Provincial Authority of Genoa: River basin planning of the Bisagno creek, http://cartogis.provincia.genova.it/cartogis/pdb/ bisagno (last access: July 2015), 2001.

Quevauviller, P. (Ed.): Hydrometeorological hazards, interfacing science and policy, Wiley Blackwell, Chapter 3.1, 2014.

Rebora, N., Ferraris, L., von Hardenberg, J., and Provenzale, A.: Rainfall downscaling and flood forecasting: a case study in the Mediterranean area, Nat. Hazards Earth Syst. Sci., 6, 611-619, doi:10.5194/nhess-6-611-2006, 2006a.

Rebora, N., Ferraris, L., Hardenberg, J. H., and Provenzale, A.: The RainFARM: Rainfall Downscaling by a Filtered Auto Regressive Model, J. Hydrometeorol., 7, 724-738, 2006b.

Rebora, N., Molini, L., Casella, E., Comellas, A., Fiori, F., Pignone, F., Siccardi, F., Silvestro, F, Tanelli., S., and Parodi, A.: Extreme rainfall in the Mediterranean: what can we learn from observations?, J. Hydrometeorol., 14, 906-922, doi:10.1175/JHM-D-12083.1, 2013.

Rosso, R.: Bisagno, Il fiume nascosto, Marsilio editor, Italia, Venezia, 98-99, 2014.

Roth, G., Barrett, E., Giuli, D., Goddard, J., Llasat, M., Minciardi, R., Mugnai, A., Scarchilli, G., and Siccardi, F.: The STORM Project: Aims, objectives and organisation, Remote Sens. Rev., 14, 23-50, 1996.

Rudari, R. and the RASOR Team: RASOR Project: Rapid Analysis and Spatialisation of Risk, from Hazard to Risk using EO data, Geophys. Res. Abstr., Vol. 17, EGU2015-2538, EGU General Assembly 2015, 2015.

Siccardi, F., Boni, G., Ferraris, L., and Rudari, R.: A hydrometeorological approach for probabilistic flood forecast, J. Geophys. Res, 110, D05101, doi:10.1029/2004JD005314, 2005.

Silvestro, F. and Rebora, N.: Impact of precipitation forecast uncertainties and initial soil moisture conditions on a probabilistic flood forecasting chain, J. Hydrol., 519, 1052-1067, 2014.

Silvestro, F., Rebora, N., and Ferraris, L.: Quantitative flood forecasting on small and medium size basins: a probabilistic approach for operational purposes, J. Hydrometeorol., 12, 14321446, 2011.

Silvestro, F., Gabellani, S., Giannoni, F., Parodi, A., Rebora, N., Rudari, R., and Siccardi, F.: A Hydrological Analysis of the 4th November 2011 event in Genoa, Nat. Hazards Earth Syst. Sci., 12, 2743-2752, doi:10.5194/nhess-12-2743-2012, 2012.

Silvestro, F., Gabellani, S., Delogu, F., Rudari, R., and Boni, G.: Exploiting remote sensing land surface temperature in distributed hydrological modelling: the example of the Continuum model, 
Hydrol. Earth Syst. Sci., 17, 39-62, doi:10.5194/hess-17-392013, 2013.

Silvestro, F., Rebora, N., Cummings, G., and Ferraris, L.: Experiences of dealing with flash floods using an ensemble hydrological nowcasting chain: implications of communication, accessibility and distribution of the results, J. Flood Risk Manag., doi:10.1111/jfr3.1216, 2015a.

Silvestro, F., Rebora, N., Giannoni, F., Cavallo, A., and Ferraris, L.: The flash flood of the Bisagno Creek on 9th October 2014: an "unfortunate" combination of spatial and temporal scales, J. Hydrol., doi:10.1016/j.jhydrol.2015.08.004, 2015b.

Silvestro, F., Gabellani, S., Rudari, R., Delogu, F., Laiolo, P., and Boni, G.: Uncertainty reduction and parameter estimation of a distributed hydrological model with ground and remote-sensing data, Hydrol. Earth Syst. Sci., 19, 1727-1751, doi:10.5194/hess19-1727-2015, 2015c.
Sinclair, S. and Pegram, G.: Combining radar and rain gauge rainfall estimates using conditional merging, Atmos. Sci. Lett., 6, 19-22, 2005.

Trasforini, E., De Angeli, S., Fiorini, M., Rossi, L., and Rudari, R.: Use of crowd source, Open Data and EO-based information in flood damage assessment: the 2014 urban flood in Genoa, Geophys. Res. Abstr., Vol. 17, EGU2015-11756, 2015 EGU General Assembly, 2015.

Versini, P. A., Berenguer, M., Corral, C., and Sempere-Torres, D.: An operational flood warning system for poorly gauged basins: demonstration in the Guadalhorce basin (Spain), Nat Hazards, 71, 1355-1378, 2014.

Wu, S. S., Qiu, X., and Wang, L.: Population Estimation Methods in GIS and Remote Sensing: AReview, Gisci. Remote Sens., 42, 80-96, doi:10.2747/1548-1603.42.1.80, 2005. 